\title{
Chikungunya outbreak in the Caribbean region, December 2013 to March 2014, and the significance for Europe
}

W Van Bortel (wim.vanbortel@ecdc.europa.eu) ${ }^{1}$, F Dorleans ${ }^{2}$, J Rosine ${ }^{2}$, A Blateau², D Rousset ${ }^{3}$, S Matheus ${ }^{3}$, I Leparc-Goffart ${ }^{4}$,

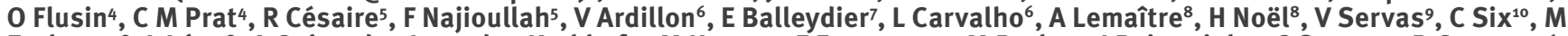
Zurbaran $^{8}$, L Léon ${ }^{8}$, A Guinard ${ }^{11}$, J van den Kerkhof ${ }^{12}$, M Henry ${ }^{13}$, E Fanoy ${ }^{12,14,15}$, M Braks ${ }^{12}$, J Reimerink ${ }^{12}$, C Swaan ${ }^{12}$, R Georges ${ }^{16}$, L Brooks $^{17}$, J Freedman ${ }^{18}$, B Sudre ${ }^{1}$, H Zeller $^{1}$

1. European Centre for Disease Prevention and Control, Stockholm, Sweden

2. French Institute for Public Health Surveillance, Fort-de-France, Martinique

3. National Reference Centre, Institut Pasteur de la Guyane, Cayenne, French Guiana

4. National Reference Centre, IRBA, Marseille, France

5. University Hospital Laboratory of virology, Fort-de-France, Martinique

6. French Institute for Public Health Surveillance, Cayenne, French Guiana

7. French Institute for Public Health Surveillance, Saint-Denis, La Réunion

8. French Institute for Public Health Surveillance, Paris, France

9. French Institute for Public Health Surveillance, Bordeaux, France

10. French Institute for Public Health Surveillance, Marseille, France

11. French Institute for Public Health Surveillance, Toulouse, France

12. National Institute for Public Health and the Environment, Bilthoven, The Netherlands

13. Section General Public Health of the Department of Collective Prevention Services, Sint Maarten

14. European Programme for Intervention and Epidemiology Training, Stockholm, Sweden

15. Public Health Service Region of Utrecht, Zeist, the Netherlands

16. Ministry of Health and Social Development, British Virgin Islands

17. Ministry of Social Development, Government of Anguilla

18. Public Health England, United Kingdom

Van Bortel W, Dorleans F, Rosine J, Blateau A, Rousseau D, Matheus S, Leparc-Goffart I, Flusin O, Prat CM, Césaire R, Najioullah F, Ardillon V, Balleydier E, Carvalho L, Lemaître A, Noël H, Servas V, Six C, Zurbaran M, Léon L, Guinard A, van den Kerkhof J, Henry M, Fanoy E, Braks M, Reimerink J, Swaan C, Georges R, Brooks L, Freedman I, Sudre B, Zeller H. Chikungunya outbreak in the Caribbean region, December 2013 to March 2014, and the significance for Europe. Euro Surveill. 2014;19(13): pii=20759. Available online: http://www.eurosurveillance.org/ViewArticle.aspx?Articleld=20759

On 6 December 2013, two laboratory-confirmed cases of chikungunya without a travel history were reported on the French part of the Caribbean island of Saint Martin, indicating the start of the first documented outbreak of chikungunya in the Americas. Since this report, the virus spread to several Caribbean islands and French Guiana, and between 6 December 2013 and 27 March 2014 more than 17,000 suspected and confirmed cases have been reported. Further spread and establishment of the disease in the Americas is likely, given the high number of people travelling between the affected and non-affected areas and the widespread occurrence of efficient vectors. Also, the likelihood of the introduction of the virus into Europe from the Americas and subsequent transmission should be considered especially in the context of the next mosquito season in Europe. Clinicians should be aware that, besides dengue, chikungunya should be carefully considered among travellers currently returning from the Caribbean region.

\section{Introduction}

Chikungunya is a mosquito-borne viral disease caused by an alphavirus from the Togaviridae family. The virus is transmitted by the bite of Aedes mosquitoes, primarily Aedes aegypti and Aedes albopictus. The typical clinical signs of the disease are fever and severe arthralgia, which may persist for weeks, months or years after the acute phase of the infection [1]. General complications include myocarditis, hepatitis, ocular and neurological disorders [2]. The detection and diagnosis of the disease can be challenging especially in settings where dengue is endemic. It was estimated that three to $25 \%$ of infected individuals are asymptomatic. Blood-borne transmission is possible [3,4] and mother-to-child transmission has also been reported in newborns of viraemic women who developed the disease within the week prior to delivery $[5,6]$.

Chikungunya has been, up to 2005 , found to be endemic in parts of Africa, south-east Asia and on the Indian subcontinent (see historical overview: Figure 1). Prior to 2005 , outbreaks occurred mainly in the well-known endemic areas. From 2005 to 2006 , large chikungunya outbreaks were reported from Comoros, Mauritius, Mayotte, Réunion and various Indian states (Figure 1). In 2013, chikungunya outbreaks occurred in a variety of geographic locations within India (Gujarat, Tamil Nadu, Kerala, Odisha states), Indonesia (East Jakarta, East Java), Micronesia (Yap), the Philippines archipelago, including the city of Manila, as well as Singapore, and the first evidence of autochthonous transmission 
Historical overview of the chikungunya outbreaks prior to the emergence of the chikungunya virus in the Caribbean in December 2013

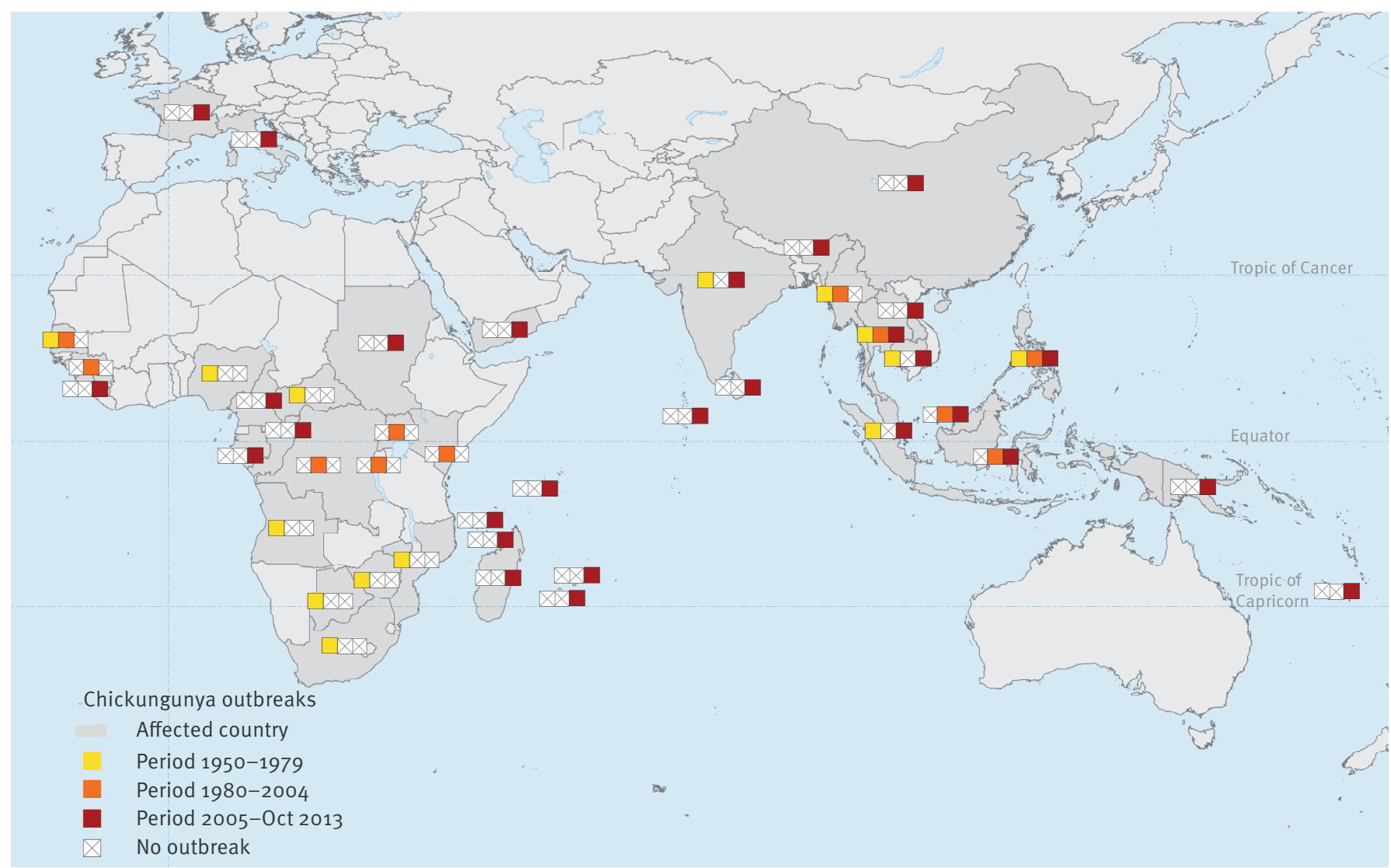

The Figure is based on references [29-81]. The detection of the chikungunya virus in the Caribbean in December 2013 constitutes the first finding of the virus in the Americas, therefore this region of the world is not shown on the map. Each square represents a particular period: the left square represents period 1950-1979, the middle square period 1980-2004 and the right square period 2005-0ctober 2013. The squares are coloured yellow, orange and red respectively when an outbreak was reported in the literature. Otherwise the square is white-crossed.

in New Caledonia and Papua New Guinea was reported in June 2012 (Figure 1 and [7]). Autochthonous transmission in continental Europe was first reported from Emilia-Romagna, Italy, in August 2007 with more than 200 confirmed cases [8] and subsequently in 2010 in the Var, France with two confirmed cases [9]. In both areas the vector Ae. albopictus is established [10].

Three different genotypes of chikungunya virus, namely Asian, West African, and East/Central/South African (ECSA), have been identified. The acquisition of an A226V mutation in the envelope protein $E_{1}$ of ECSA chikungunya virus, as observed in Réunion in 2005, increased the transmissibility of the virus by the widely distributed Ae. albopictus mosquitoes [11]. This mutated virus spread from the Indian Ocean to East Africa and Asia and was involved in the chikungunya outbreak in Italy [8]. Phylogenetic analysis proved that the chikungunya virus responsible for autochthonous cases in France belonged to the ECSA strain, but without the mutation at position 226 [9].
On 6 December 2013, two laboratory-confirmed cases of chikungunya without a travel history were reported on the French part of the Caribbean island of Saint Martin in the context of a dengue outbreak occurring on this island [12] and the virus spread since then to other islands in the Caribbean. This is the first documented outbreak of chikungunya with autochthonous transmission in the Americas. This paper aims to review the current epidemiological situation of chikungunya in the Caribbean region, to assess its significance for both the region and the European Union (EU) and to provide an historical overview of the geographical emergence of chikungunya.

\section{Epidemiology of chikungunya in the Caribbean}

The Caribbean French overseas territories: French Guiana, Guadeloupe, Martinique, Saint Barthélemy and Saint Martin

The Caribbean French overseas territories include the islands Guadeloupe, Martinique, Saint Barthélemy 
Number of confirmed and estimated suspected chikungunya cases reported in the Caribbean by week of sampling, 1 December 2013-23 March 2014

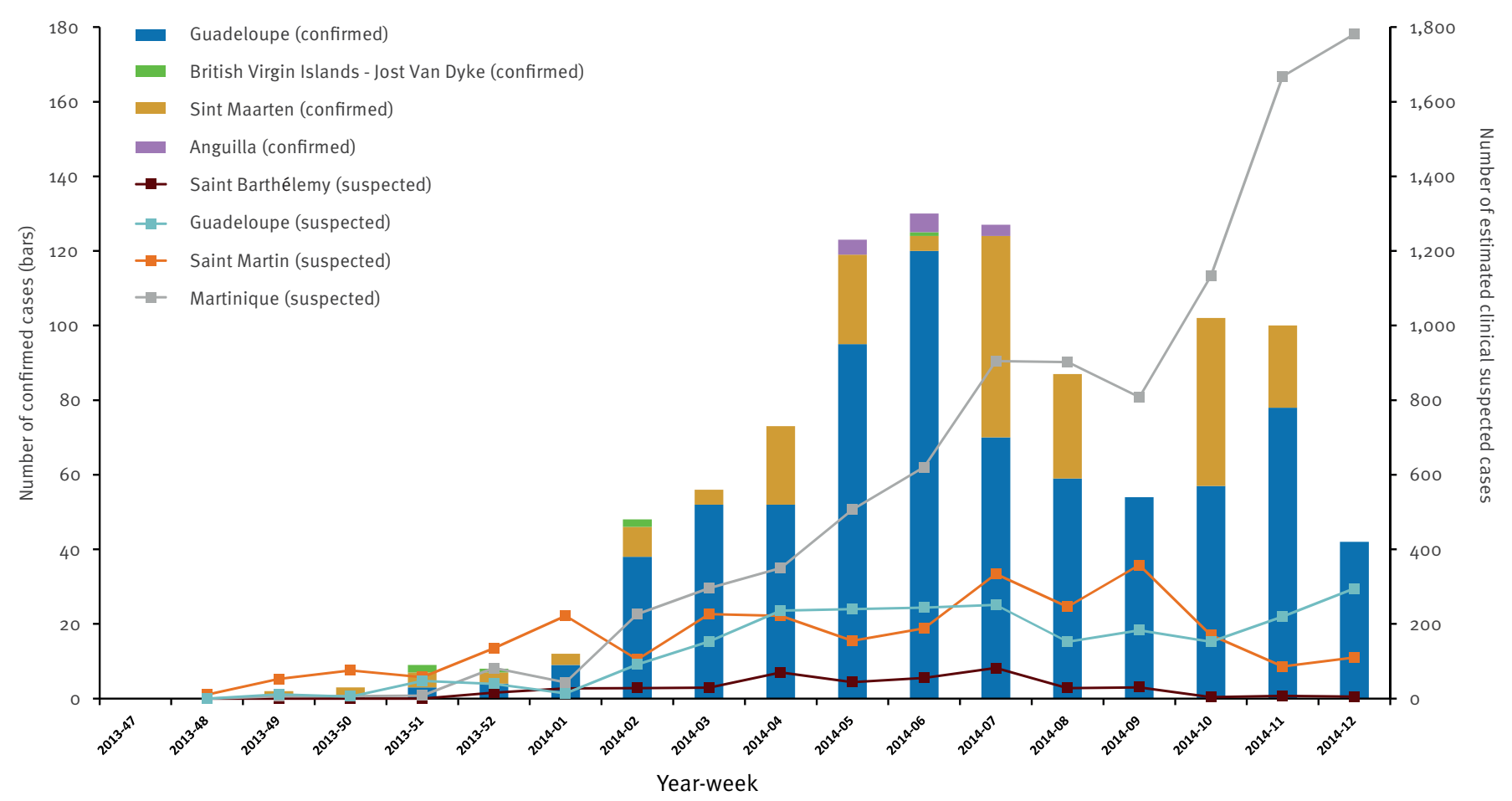

The period 1 December 2013-23 March 2014 corresponds to week 48 2013-week 12 2014. From week 52014 onwards the expert committee for emerging and infectious diseases of Martinique, Saint Barthélemy and Saint Martin recommended to focus the laboratory diagnostics on patients for which laboratory confirmation is needed to support case management. From then, the systematic confirmation of cases was ceased on these islands. Therefore the confirmed cases (bars) are only shown for Anguilla, Guadeloupe, Jost Van Dyke and Sint Maarten. Estimated numbers of suspected clinical cases (lines) are respectively provided for Guadeloupe, Martinique, Saint Barthélemy, and Saint Martin.

and Saint Martin, and French Guiana on the South American continent. Dengue surveillance and control are well established on the Caribbean French overseas territories.

In mid-November 2013, the suspicion of autochthonous transmission of chikungunya virus on the island of Saint Martin was brought to the attention of the local health authorities. On 6 December 2013, a first suspected case of chikungunya occurring in the French part of the island was laboratory confirmed and an outbreak phase was declared the same day for Saint Martin.

Following this confirmation, enhanced surveillance for chikungunya cases was implemented not only in Saint Martin but also in the other Caribbean French overseas territories, because intense travel of people occurs between the affected island and these neighbouring territories. Based on the phase of the outbreak in the different territories - each territory declares the outbreak-phase based on their assessment/context the following components of the surveillance system were either implemented or strengthened to achieve the early detection of suspected chikungunya cases and to monitor the evolution of the epidemic. (i) During the pre-outbreak phase, i.e. when the first autochthonous cases are detected and laboratory confirmed, the surveillance focussed on systematic confirmation of cases. Therefore, general practitioners and medical microbiologists were invited to report all clinical suspected cases of chikungunya using a specific notification form. A clinical suspected case was defined as any individual with sudden onset of fever $\left(>38.5^{\circ} \mathrm{C}\right)$ with arthralgia and without any other aetiology. Laboratory investigations were systematically conducted on all clinical suspected cases. A confirmed case was defined as a clinical suspected case with laboratory confirmation, either a positive reverse transcription-polymerase chain reaction (RT-PCR) or a positive detection of IgM and IgG or both; (ii) once the outbreak was declared by the local authorities, i.e. the outbreak phase, the surveillance was performed through the weekly notification of clinical suspected cases by the sentinel network of general practitioners; in Saint Martin, all general practitioners and one paediatrician were asked to report the number of clinical suspected cases. Further all hospitals in the territories had to weekly notify emergency room visits for suspected cases, and hospital admissions for confirmed cases. The systematic 
Local chikungunya transmission and imported cases in the islands of the Caribbean region and in French Guiana, 1 December 2013-23 February 2014

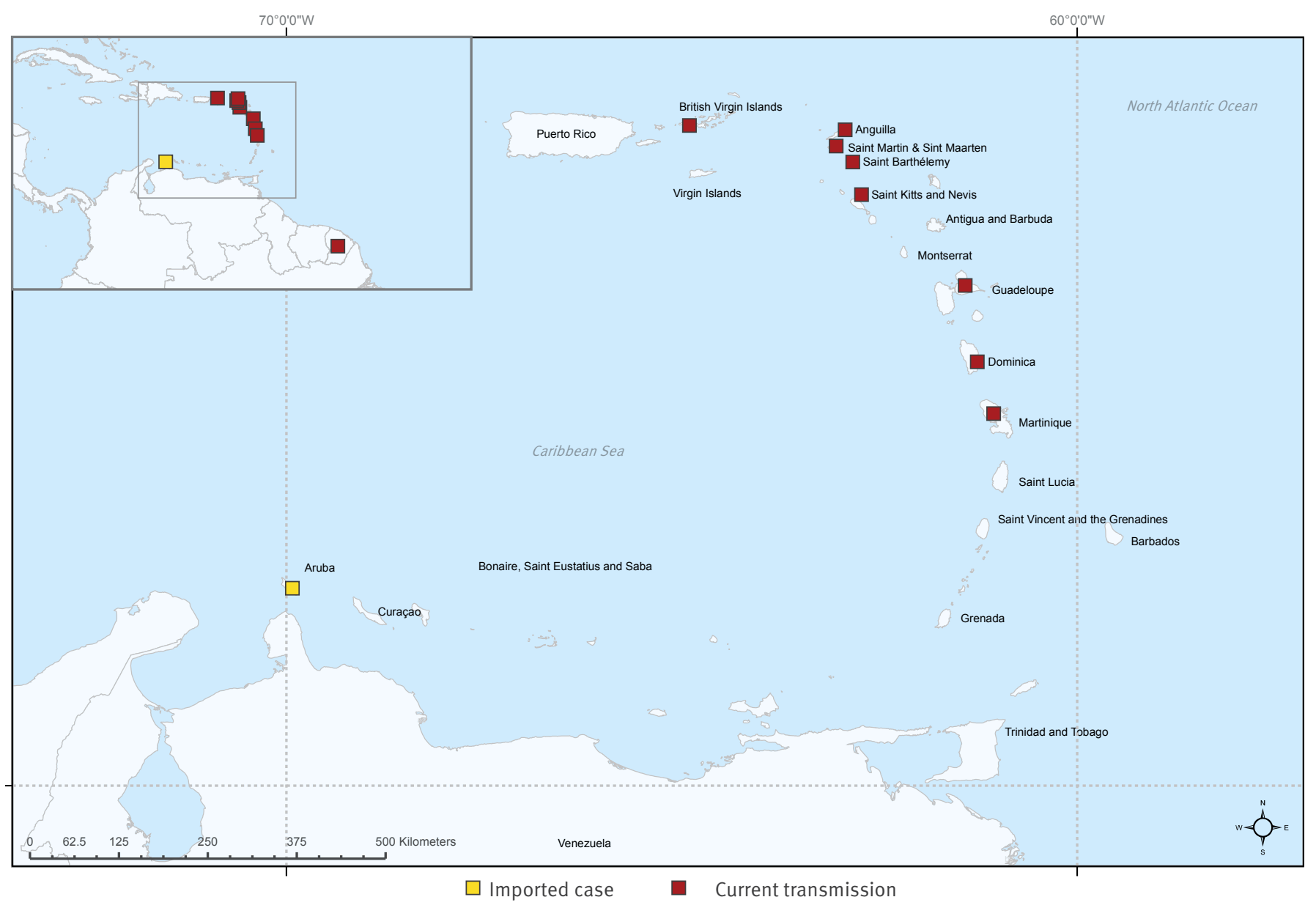

The period 1 December 2013-23 February 2014 corresponds to week 482013 -week 82014.

laboratory confirmation of all suspected cases was ceased in week 52014 in Martinique, Saint Barthélemy and Saint Martin to prevent overloading the laboratories performing the diagnosis.

Strengthened surveillance enabled the detection of confirmed cases of chikungunya on French territories other than Saint Martin. Data were collected at the local level and regional level (i.e. the Regional Office of the French Institute for Public Health Surveillance, Fort-de-France, Martinique) in order to follow the progression of the virus in the different territories (French Guiana, Guadeloupe, Martinique, Saint Barthélemy, Saint Martin), to coordinate the activities and to harmonise common tools (questionnaires, templates, protocols) used during the pre-outbreak and outbreak management phases.

\section{Epidemiological situation}

Since the introduction of the chikungunya virus in Saint Martin and subsequent implementation of enhanced surveillance, the first cases in Martinique, Guadeloupe, Saint Barthélemy and French Guiana were confirmed on 18, 24, 30 December 2013 and 19 February 2014 respectively. Since the start of the outbreak the number of suspected and confirmed cases increased indicating continuous transmission of the virus in all affected territories (Figure 2).

As of 27 March 2014, the estimated number of clinical suspected cases of chikungunya in Saint Martin was 2,750 and the number of confirmed cases was 784 (week 482013 to 12 2014). Three deaths indirectly related to chikungunya were reported.

A total of 435 clinical suspected cases were estimated on the island of Saint Barthélemy and 134 infections have been confirmed (week 502013 to 12 2014).

In Martinique, 9,340 clinical suspected cases of chikungunya were estimated (week 492013 to 12 2014) and 1,207 cases were identified as laboratory-confirmed 
Weekly incidence of the estimated suspected cases of chikungunya by the sentinel network in Guadeloupe, Martinique, Saint Barthélemy and Saint Martin, 1 December 2013-26 January 2014

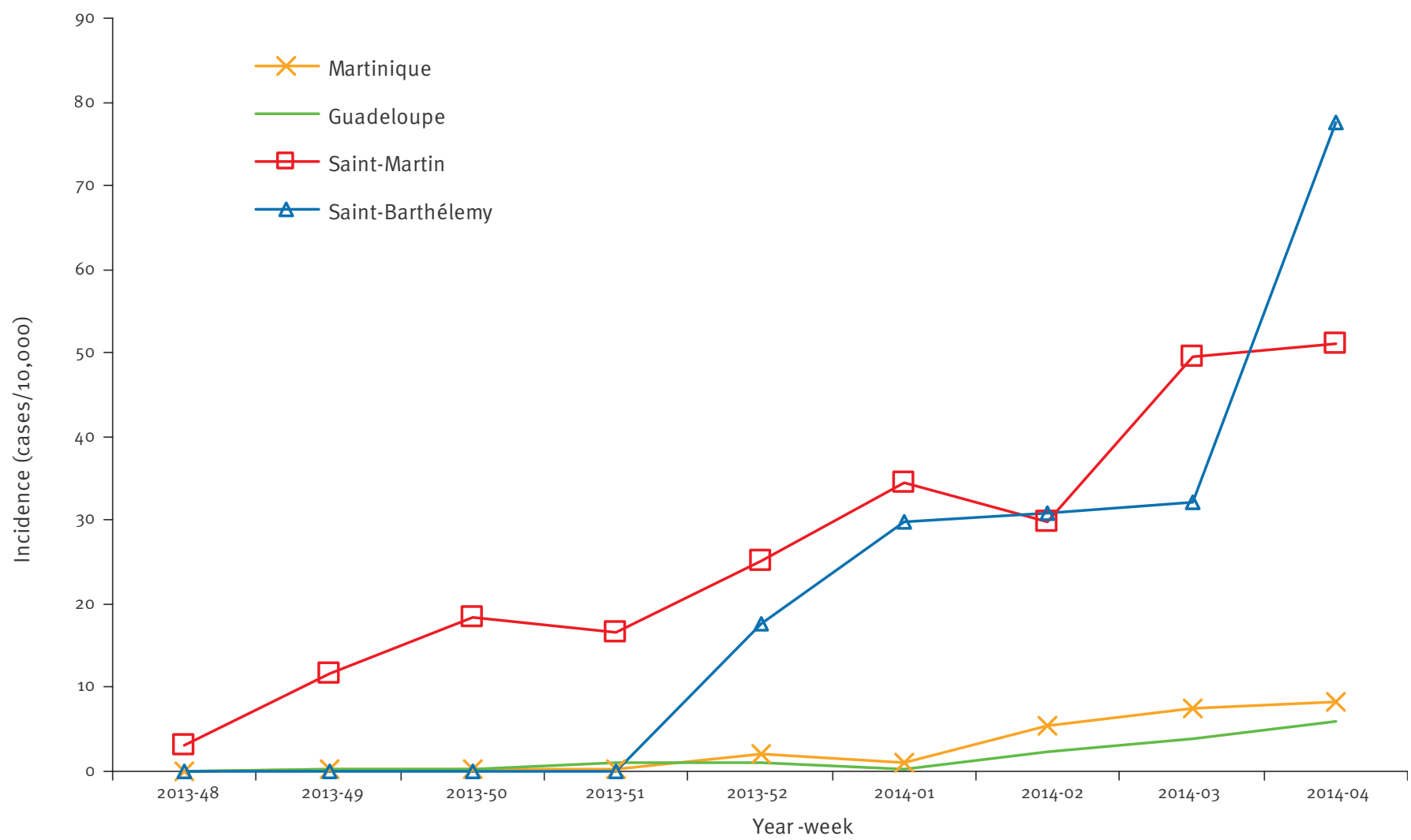

The period 1 December 2013-26 January 2014 corresponds to the weeks 48 2013-42014.

cases. Two deaths were reported in Martinique in hospitalised patients: one death was classified as indirectly linked with chikungunya; the second death is under investigation.

In Guadeloupe, a total of 2,270 clinical suspected cases were estimated to have occurred (week 522013 to 12 2014) and 734 cases were confirmed for the infection in this island (Figures 2 and 3).

A rapid increase of the weekly incidence was observed in the smaller islands Saint Martin (population: 36,029) and Saint Barthélemy (population: 9,035) compared to the larger islands Martinique (population: 392,290) and Guadeloupe (population: 404,640) (Figure 4).

Since the beginning of the outbreak, 11 cases from Saint Martin and Martinique were imported in French Guiana. The first autochthonous cases in French Guiana were reported on 19 February, with a total of 24 autochthonous laboratory-confirmed cases in week 112014.

In Saint Martin, all areas of the island have been affected by the virus, a predominant number of confirmed cases occurred in Sandy Ground, Concordia and
Quartier d'Orléans. In Martinique, the outbreak is geographically generalised. The main city, Fort-de-France, had the highest attack rate (estimated from the weekly number of notifications of clinical suspected cases) followed by, La Trinité, Case Pilote, Schoelcher, SaintPierre, and Les Anses d'Arlet. The main cluster identified in Guadeloupe was located in Baie-Mahault and in other municipalities of the windward shore of Basse Terre. In total, 27 of 32 municipalities had at least one confirmed case.

\section{Microbiological investigation}

Before the outbreak phase, laboratory confirmation was requested for every clinical suspected case of chikungunya. The diagnostic algorithm was intended to be followed by practitioners and microbiological laboratories. The samples were processed according to the date of the onset of symptoms and the date of sample collection. When the sample was taken between the first and fifth day after symptom onset, the sample was processed by RT-PCR. When the sample was taken between the fifth and the seventh day after symptoms onset, the sample was processed both by RT-PCR and detection of IgM and IgG, for the remainder only IgM and IgG detection was performed. 
Because both dengue and chikungunya viruses are currently circulating, dengue diagnostic was systematically performed parallel to chikungunya laboratory tests. The microbiological analysis strategy was adapted according to the respective outbreak situation. In the territories where there was evidence of wide virus spread, only at-risk patients (when laboratory confirmation was needed to support the case management) and uncommon forms of the infection were targeted for laboratory confirmation (Martinique, Saint Barthélemy and Saint Martin, from week 5 2014). Local, regional and national capacities support the diagnostic strategy of the region (National Reference Laboratories and hospital-based microbiological laboratories).

On 10 December 2013, five days after the detection of the first autochthonous cases in Saint Martin, the complete chikungunya virus sequence showed that this virus belongs to the Asian genotype and the information was shared with the relevant public health authorities [13].

\section{Control measures}

All houses and work places of confirmed cases were targeted by vector control measures as scheduled in the Management, Surveillance and Alert of chikungunya outbreak Programme, which was implemented as a result of the outbreak. Epidemiological and entomological investigations were conducted simultaneously in the neighbouring environment of the suspected and confirmed cases (during pre-outbreak and outbreak phases) as well as interventions on the whole territory (outbreak phase), to identify possible clusters of cases and to implement vector control targeting adult mosquitoes and their breeding sites.

Public education was established through radio spots, television, distribution of flyers and posters with prevention messages in public areas, airports, private practitioner's offices, hospitals and clinics. The health authorities also implemented a specific programme preventing possible shortage of healthcare capacities due to the high burden of patients on emergency, hospital and outpatient capacities.

\section{Overseas territories of the Netherlands}

The overseas territories of the Netherlands in the Caribbean region comprise six islands grouped in three smaller Windward Islands in the north, and three larger Leeward Islands in the south, just north of the Venezuelan coast. The total population of these islands is 320,000 and ranges from 2,000 (Saba) to over 147,000 (Curaçao). The three islands with a larger population, Aruba, Curaçao, and Sint Maarten, are independent states within the Netherlands, the other three islands (Bonaire, Sint Eustatius and Saba), the so-called BES islands, have the status of special municipalities within the Netherlands. Sint Maarten (close to 40,000 inhabitants) is the southern part of the island of which the Northern part is formed by Saint Martin.
Epidemiological situation

The first report of laboratory-confirmed autochthonous chikungunya case in the overseas territories of the Netherlands was received by section General Public Health of the Department of Collective Prevention Services in Sint Maarten on 22 December 2013. The case had had onset of illness on 6 December 2013. Since the start of the outbreak, the total number of confirmed patients diagnosed with chikungunya on Sint Maarten has been 234 (up to week 11 2014), including one hospitalised case. The Dutch case definition for confirmed cases is fever $\left(38.5^{\circ} \mathrm{C}\right)$ and joint pain in a person who has a positive polymerase chain reaction $(P C R)$ and/or specific positive IgM antibody test. The proportion of test-positive samples increased from 29\% (2/7) in December 2013 up to 69\% (77/111) at the end of March 2014. The Caribbean Public Health Association (CARPHA) is, amongst other activities, assisting the countries and territories in the Caribbean region in the surveillance of communicable diseases. In this context they operate a syndromic surveillance system. Data from the surveillance showed for Sint Maarten an average and stable number of patients with undifferentiated fever since December 2013. Since the end of January 2014 , start of week 5 , the syndromic surveillance showed a consistently higher number of cases of undifferentiated fever compared to the historical average, generally below five cases per week based upon four years of data. Since week 5 , cases vary between two and 34 per week (an average of 13 per week between week 5 and 12). Although there has been an ongoing dengue outbreak during this period, the increase is likely to be due to chikungunya, given that dengue season started well before January.

The number of confirmed cases on Sint Maarten $(n=234)$ is much lower than on Saint Martin $(n=784)$ although the number of inhabitants of both parts of the island is comparable (ca. 40,000). Because of intense traffic occurs between the two parts of the island and ecological barriers are absent, there is no obvious reason why the disease would be more prominent in the northern than in the southern part of this small island $\left(87 \mathrm{~km}^{2}\right)$. More likely, the difference in the number of reported cases is due to the difference in the availability of diagnostic testing and under-reporting. Twelve patients from Sint Maarten were diagnosed by general practitioners from Saint Martin. From the epidemiological data currently available, the residencies of most patients cannot be identified in a reliable manner.

The other two Dutch Windward islands, Saba and Sint Eustatius, have small populations (2,000 and 3,900) of which no patients have been diagnosed so far. The syndromic surveillance on these islands shows a low and stable number of patients with undifferentiated fever since December 2013. A rise in these figures could be an early signal for emergence of chikungunya. In the Dutch Leeward Islands, Aruba, Bonaire and Curaçao, no autochthonous cases have been identified so far. One imported confirmed case returning from Saint 
Martin was reported on the island of Aruba in the first week of February 2014 (Figures 2 and 3).

\section{Microbiological investigation}

The first three patients from Sint Maarten were diagnosed by the French National reference laboratory (CNRIRBA Marseille) using RT-PCR testing. On January 2014 , serum samples from Sint Maarten were sent to the virological laboratory of the National Institute for Public Health and the environment (RIVM) in Bilthoven, which made diagnostic testing available. Reference materials were obtained from the laboratory in Marseille (CNRIRBA). Due to a lack of information about the date of onset of illness, all samples were tested by RT-PCR and for chikungunya-specific IgM and IgG-antibodies when RT-PCR was negative. Because transport of samples is both expensive and time consuming, the RIVM assists the local laboratories of Sint Maarten and Curaçao to implement serological testing indirect fluorescent-antibody (IFA) from the second quarter of 2014.

\section{Control measures}

Mosquito control services are present on Sint Maarten and routine measures are the same as for the control of dengue fever: fogging with adulticides (Evoluer 4-4; active ingredient: permethrin/piperonyl butoxide), removal of breeding sites, application of larvicides in water containers and health education on prevention of mosquito bites. Upon arrival, tourists, which are paramount for the regional economy of the islands, are informed of the ongoing outbreak of chikungunya and advised to take personal protection measures against mosquito bites. The local authorities make use of the preparedness and response plan of the United States (US) Centers for Disease Control and Prevention (CDC) for introduction of chikungunya virus in the Americas, which was introduced during two workshops in 2012 hosted by Pan American Health Organization (PAHO) [14]. Specialists from the CARPHA and the PAHO have provided expert advice concerning control in January 2014 by means of a work visit to Sint Maarten. General practitioners have been informed of the presence of the disease and an intensified surveillance has been initiated by the Public Health Authority of Sint Maarten. The ministry of Health has initiated procedures in order to make chikungunya cases notifiable for the BES islands. General practitioners and specialists on all other overseas territories in the Netherlands have been informed of this emerging epidemic, and have been advised concerning diagnostic testing since the end of December 2013.

\section{Overseas territories of the United Kingdom}

The overseas territories of the United Kingdom (UK) in the Caribbean region comprise five territories of which three (Anguilla, British Virgin Islands and Montserrat) are located within the Lesser Antilles east of Puerto Rico and two (Cayman Islands and Turks and Caicos Islands) in the western Caribbean in the Greater Antilles. The total population of these territories is around 136,000 and ranges from just over 5,000 (Montserrat) to around
53,200 (Cayman Islands). All are internally self-governing UK overseas territories.

A standard case reporting form is used to collect information on chikungunya cases (based on the case definition). Reports from undifferentiated fever $\left(38.5^{\circ} \mathrm{C}\right)$, which might include chikungunya cases, are collected on a weekly basis from sentinel sites.

Epidemiological situation

British Virgin Islands: three cases of chikungunya were confirmed by CAPHA on Jost Van Dyke island in the British Virgin Islands on 13 January 2014 (Figures 2 and 3). The cases had onset of symptoms on the 15,17 and 25 December 2013. The symptom profile of the three cases consisted of fever $\left(338.5^{\circ} \mathrm{C}\right)$ and severe arthralgia. Retro-orbital pain, back pain, and rash were not present. There was no history of travel. These three cases tested positive for chikungunya and were negative for dengue by PCR. As of 27 March 2014, a total of seven autochthonous cases have been confirmed in the British Virgin Islands, all from Jost Van Dyke island; the most recent case with onset of illness on 5 February 2014 (week 6 2014).

Anguilla: On 31 January 2014, one case of chikungunya, believed to be imported from Saint Martin was diagnosed in Anguilla and confirmed by CARPHA in Trinidad. As of 27 March, a total of 14 confirmed cases (13 autochthonous and one imported) have been reported in Anguilla with onsets of illness between 27 January and 16 February 2014.

The case definition used is in line with the one provided by CARPHA: a suspected case is a patient with acute onset of fever $338.5^{\circ} \mathrm{C}$ and severe arthralgia or arthritis not explained by other medical conditions, and who resides or has visited epidemic or endemic areas within two weeks prior to the onset of symptoms; a probable case is defined as a suspected case with a positive result for chikungunya by IgM enzyme-linked immunosorbent assay (ELISA); and a confirmed case is a suspected case with a positive result for chikungunya by viral isolation, RT-PCR or four-fold increase in chikungunya virus specific antibody titres (samples collected at least 2 to 3 weeks apart).

\section{Microbiological investigation}

Molecular PCR testing for chikungunya is undertaken by CARPHA in Trinidad and the first positive samples in British Virgin Islands were sent to the US CDC for verification, as these were the first cases confirmed by the Trinidad laboratory.

\section{Control measures}

The vector control unit of the Environmental Health Division of the British Virgin Islands performed control activities and monitoring as well as house to house inspections and education at the time of the initial reports. They have been monitoring mosquito indices on Jost Van Dyke. Surveillance activities have 
been increased. The Ministry of Health and Social Development in Anguilla continues to work in collaboration with the relevant agencies to ensure that the appropriate preventative measures are implemented to reduce and contain the spread of the virus. Measures include mass education of the public to raise awareness of symptoms and prevention, fogging in areas where confirmed or suspected cases of chikungunya have been reported and engaging with port health teams at sea and airports in order to implement appropriate controls.

\section{Discussion}

Chikungunya is endemic in Africa, south-east Asia and on the Indian subcontinent with outbreaks occurring beyond the well-known endemic areas from 2005 (Figure 1). Compared to this historical occurrence, this is the first documented outbreak of chikungunya in the Americas. The virus in the Caribbean belongs to the Asian genotype [13]. It might have been introduced by travellers from Asia where outbreaks were reported in 2013. With the increased transmission of chikungunya in Asia and Africa in the last decade, the Caribbean region has been considered highly vulnerable [14]. The primary vector, Ae. aegypti, is widespread in the region [15], but also Ae. albopictus is found in the Americas and on a number of Caribbean islands [16]. The latter species has not been found in French Guiana, the French Caribbean islands nor the Dutch Caribbean territories but the climate suitability model revealed that the area is highly suitable for this vector species [15-17]. The presence of a human population naïve to the chikungunya virus, competent vectors in the region and the intense movement of people into and between islands are factors that most likely contributed to the extension of the virus circulation. Indeed, contacts between the islands are high as exemplified by the increased traffic between Saint Martin/Sint Maarten and the British Virgin Islands as a consequence of a boat show in the British Virgin Islands in December 2013. Besides the reported affected areas of the French, Dutch and British overseas territories, confirmed cases were reported from Dominica and Saint Kitts and Nevis (Figure 3 and $[18,19])$ and the first autochthonous transmission on the continent was confirmed in French Guiana 11 weeks after the first confirmed case on Saint Martin (week 8 2014). The establishment of autochthonous transmission following importation of viraemic patients in other territories of the Americas is expected and will likely have a significant public health impact in the region. Surveillance in the region, which is well established for dengue, has been intensified and laboratory testing has been strengthened in collaboration with regional or international reference laboratories. Further, a close follow-up of the situation and co-ordinated surveillance and control within the regions is still needed.

The vulnerability of Europe for the transmission of chikungunya virus and other arboviruses was recognised prior to 2007 [20] and confirmed with the first chikungunya outbreak in Italy in 2007 [8,21,22]. For onward transmission to occur, the introduction of this virus into Europe would need to coincide with high vector abundance and activity i.e. during the summer season in the EU. Hence, chikungunya outbreaks in the northern hemisphere are of bigger concern for the EU than those in the southern hemisphere [23]. During the period from 2008 to 2012, 475 imported chikungunya cases have been reported by 22 EU/European Economic Area (EEA) countries [7]. Most cases originated from Asia (one third from India, otherwise Indonesia, Maldives, Sri Lanka and Thailand) and Africa (including islands from the Indian Ocean). Temporal clusters of chikungunya cases imported in the EU are largely synchronous with large outbreaks in endemic countries as reported for Germany [24]. The occurrence and possible establishment of chikungunya in the Caribbean region adds an additional possible source of introduction of the virus. Because of the relatively intensive traffic between the overseas territories and the EU, introduction of chikungunya in Europe can be anticipated and blood safety measures could be considered [25]. It should be noted that both autochthonous dengue cases in France in 2010 and 2013 followed the introduction of a viraemic patient from the French Caribbean overseas territories. The introduction of chikungunya viraemic persons will most likely not lead to onwards transmission in Europe during the winter season as the vectors are not active during this season. However, vigilance is needed if the outbreak in the Caribbean region continues and overlaps with the mosquito vector season in areas where Ae. albopictus is established in continental Europe.

Firstly reported in Europe in 1979 in Albania [26], the mosquito vector Ae. albopictus has continuously expanded its distribution in the EU. To date this species has colonised almost all Mediterranean countries and has been found introduced, without establishment in Austria, Belgium, Czech Republic, in more northern localities in France, and the Netherlands, [10]. Ae. albopictus can reach high densities from July to September around the Mediterranean where it is established [27]. Ae. aegypti has recently established on Madeira and is found around the Black Sea coast. The A226V mutation of ECSA chikungunya virus has increased the transmissibility of the chikungunya virus by $A e$. albopictus [11] and vector competence studies using Ae. albopictus populations from France showed that both the mutated and non-mutated ECSA chikungunya strains can be transmitted by local mosquito populations [28]. The chikungunya strain currently circulating in the Caribbean region does not belong to the ECSA genotype but to the Asian genotype. The strain is related to strains recently identified in Indonesia, China and the Philippines [13]. The competence of the European population of Ae. albopictus to transmit this chikungunya strain needs investigation.

In conclusion, spread and establishment of the disease in the Caribbean and other regions in the Americas can be anticipated given the high connectivity between the affected and non-affected areas and the widespread 
occurrence of efficient vectors. Also, the risk of introduction of the disease to the EU from the affected territories in the Caribbean should be considered especially in the context of the next mosquito season in Europe. Clinicians should be aware that, besides dengue, chikungunya should be considered among travellers currently returning from the Caribbean region. The clinical picture of both infections can be similar and might be a challenge for clinicians that are not familiar with the clinical presentation of these infections.

\section{Acknowledgements}

We would like to thank the CVAGS in French Guiana, Guadeloupe, Martinique, Saint Barthélemy and Saint Martin, the microbiologists and the staff of the National Reference Laboratories (CNR in Irba Marseille, CNR in IPG Cayenne, RIVM-IDS in Bilthoven) and the public hospital microbiological laboratory of virology for their high commitment. We are also grateful to the sentinel doctors from Guadeloupe, Martinique, Saint Barthélemy, Saint Martin, and Sint Maarten, and the infectious diseases specialists working at the hospital Centres in the different territories and the private microbiological laboratories.

\section{Conflict of interest}

None declared.

\section{Authors' contributions}

Wim Van Bortel coordinated and drafted the manuscript, and reviewed final document for accuracy; Frédérique Dorleans coordinated and drafted the part of the manuscript on the French Caribbean territories and reviewed the different versions of the MS / Permanent member of the outbreak team management in Martinique; Jacques Rosine and Alain Blateau are permanent members of the outbreak management team in Martinique and permanent member of the regional outbreak management team (French Caribbean territories) and responsible for the data collection management and interpretation; Dominique Rousset form the French National Reference Center for Arboviruses is head of the associated lab for the French departments of the Americas and involved in virological diagnosis and manuscript proofreading; Fatiha Najioullah of the University Hospital Laboratory of virology, Fort-de-France, Martinique manages the molecular virological diagnosis and in involved in virological diagnosis and manuscript proofreading ; Raymond Césaire Head of the virology laboratory of the University Hospital Laboratory of virology, Fort-de-France, Martinique was involved in the implementation of virological diagnosis; Séverine Matheus of the French National Reference Center for Arboviruses is deputy head of the associated laboratory for the French departments of the Americas and involved in virological diagnosis and manuscript proofreading; Isabelle Leparc-Goffart Head of the French National Reference Center for Arboviruses and coordinating all French territories is involved in virological diagnosis and participated to the writing of the manuscript; Olivier Flusin of the French National Reference Center for Arboviruses, is involved in virological diagnosis and editing of the manuscript; Christine M Prat of the French National Reference Center for Arboviruses is involved in virological diagnosis and editing of the manuscript; Vanessa Ardillon is a permanent member of the outbreak management team in French Guyana and member of the regional outbreak management team (French Caribbean territories) and responsible for management, data collection and interpretation; Elsa Balleydier is temporary member of the outbreak management team in Guadeloupe, Saint Martin and Saint Barthélemy and is involved in the data collection, management and interpretation; Luisiane Carvalho is a permanent member of the outbreak management team in French Guyana and member of the regional outbreak management team (French Caribbean territories) and responsible for management, data collection, and interpretation; Audrey Lemaître is a temporary member of the outbreak management team in Saint Martin and Saint Barthélemy and involved in the data collection, management and interpretation; Lucie Léon is a temporary member of the outbreak management team in Saint Martin and Saint Barthélemy and involved in the data collection, management and interpretation; Harold Noël, Véronique Servas, Caroline Six and Manuel Zurbaran are temporary members of the outbreak team management in Saint Martin and Saint Barthélemy and responsible for data collection, management and interpretation; Anne Guinard from the French Institute for Public Health Surveillance, Toulouse, France was involved in data collection and interpretation; Hans van den Kerkhof coordinates the international aspects of control for the Netherlands, and coordinating author of the Netherlands contribution to the Euro Roundup Chikungunya ; Ewout Fanoy is responsible for the registration of cases, epidemiological analysis and reviewing manuscript; Marieta Braks is an entomologist at the RIVM and advisor/trainer for mosquito control programmes on Sint Maarten. She was involved in the editing and proof reading of the manuscript; Johan Reimerink is a senior staff in the virological Laboratory in RIVM, and responsible for Diagnostic Testing of outbreak samples; Maria Henry is in charge of surveillance and control activities Sint Maarten and reviewed the manuscript; Corien Swaan coordinates the international aspects of control for the Netherlands and contributed to the writing of the manuscript; Ronald Georges provided epidemiological information from the British Virgin Islands and reviewed manuscript; Lynrod Brooks: provided epidemiological information from Anguilla and reviewed manuscript; Joanne Freedman: provided the UK background, coordinated the contribution of additional epidemiological information from the UK overseas territories and reviewed final document for accuracy; Bertrand Sudre coordinated and developed the historical overview and the transmission map and reviewed final document ; Herve Zeller, head of the emerging and vector borne disease programme of ECDC, reviewed final document for accuracy. All authors have read and approved the manuscript.

\section{References}

1. Pialoux G, Gaüzère B-A, Jauréguiberry S, Strobel M. Chikungunya, an epidemic arbovirosis. Lancet Infect Dis. 2007;7(5):319-27. http://dx.doi.org/10.1016/ S1473-3099(07)70107-X

2. Farnon EC, Sejvar JJ, Staples JE. Severe disease manifestations associated with acute chikungunya virus infection. Crit Care Med. 2008;36(9):2682-3. http://dx.doi.org/10.1097/ CCM.obo13e3181843d 94

3. Bianco C. Dengue and Chikungunya viruses in blood donations: risks to the blood supply? Transfusion. 2008;48(7):1279-81. http://dx.doi.org/10.1111/j.1537-2995.2008.01806.x

4. Appassakij H, Khuntikij P, Kemapunmanus M, Wutthanarungsan R, Silpapojakul K. Viremic profiles in asymptomatic and symptomatic chikungunya fever: a blood transfusion threat? Transfusion. 2013;53(10 Pt 2):2567-74. http://dx.doi.org/10.1111/j.1537-2995.2012.03960.x

5. Ramful D, Carbonnier M, Pasquet M, Bouhmani B, Ghazouani J, Noormahomed T, et al. Mother-to-child transmission of Chikungunya virus infection. Pediat Infect Dis J. 2007;26(9):811-5. http://dx.doi.org/10.1097/ INF.obo13e3180616d4f

6. Gerardin P, Barau G, Michault A, Bintner M, Randrianaivo H, Choker G, et al. Multidisciplinary prospective study of motherto-child chikungunya virus infections on the island of $L a$ Reunion. PLoS Med. 2008;5(3):e60. http://dx.doi.org/10.1371/ journal.pmed.0050060 
7. European Centre for Disease Prevention and Control (ECDC). Rapid Risk Assessment. Autochthonous cases of chikungunya fever on the Caribbean island, Saint Martin. 11 December 2013. Stockholm: ECDC;2013.

8. Angelini R, Finarelli AC, Angelini P, Po C, Petropulacos K, Macini $P$, et al. An outbreak of chikungunya fever in the province of Ravenna, Italy. Euro Surveill. 2007;12(36):pii:3260.

9. Grandadam M, Caro V, Plumet S, Thiberge JM, Souares Y, Failloux AB, et al. Chikungunya virus, southeastern France. Emerg Infect Dis. 2011;17(5):910-3. http://dx.doi.org/10.3201/ eid1705.101873

10. European Centre for Disease Prevention and Control (ECDC) VBORNET - Network of medical entomologists and public health experts. Mosquito maps. Stockholm: ECDC; [Accessed 28 Feb 2014]. Available from: http://ecdc.europa.eu/en/ healthtopics/vectors/vector-maps/Pages/VBORNET_maps.aspx

11. Vazeille M, Moutailler S, Coudrier D, Rousseaux C, Khun $H$, Huerre $M$, et al. Two Chikungunya isolates from the outbreak of La Reunion (Indian Ocean) exhibit different patterns of infection in the mosquito, Aedes albopictus. PloS one. 2007;2(11):e1168. http://dx.doi.org/10.1371/journal. pone.0001168

12. Alerte "chikungunya" dans les Antilles. Point Epidemiol Cire Antilles Guyane. 2013; 2. French.

13. Leparc-Goffart I, Nougairede A, Cassadou S, Prat C, de Lamballerie X. Chikungunya in the Americas. Lancet. 2014;383(9916):514. http://dx.doi.org/10.1016/ So140-6736(14)60185-9

14. Pan-American Health Organization (PAHO). Preparedness and Response Plan for Chikungunya Virus Introduction in the Caribbean sub-region. Washington, DC: PAHO; 2013.

15. European Centre for Disease Prevention and Control (ECDC). E3 Geoportal: Aedes aegypti environmental suitability model Stockholm: ECDC; 2014. [Accessed 14 Feb 2014]. Available from: https://ezgeoportal.ecdc.europa.eu/SitePages/ Aedes\%20aegypti\%20Suitability\%20Map.aspx

16. European Centre for Disease Prevention and Control (ECDC). E3 Geoportal: Aedes albopictus (tiger mosquitoes) environmental suitability model Stockholm: ECDC; 2014. [Accessed 14 Feb 2014]. Available from: https://e3geoportal.ecdc.europa.eu/ SitePages/Aedes\%20albopictus\%20Suitability\%20Map.aspx

17. European Centre for Disease Prevention and Control (ECDC). The climatic suitability for dengue transmission in continenta Europe. Stockholm: ECDC, 2012.

18. Pan-American Health Organization (PAHO) - World Health Organization (WHO). Epidemiological update. Chikungunya fever, 21 February 2014. PAHO-WHO. [Accessed 28 Feb 2014]. Available from: http://www. paho.org/hq/index.php?option $=$ com docman\&task $=$ doc view \&gid $=24318$ \& Itemid $=$

19. Caribbean Public Health Agency (CARPHA). Chikungunya Updates: Caribbean Public Health Agency. CARPHA; 2014. [Accessed 31 Mar 2014]. Available from: http://carpha.org/ What-We-Do/Public-Health-Activities/Chikungunya

20. European Centre for Disease Prevention and Control (ECDC). Consultation on Chikungunya risk assessment for Europe. Stockholm: ECDC; 2006.

21. Rezza G, Nicoletti L, Angelini R, Romi R, Finarelli AC, Panning $M$, et al. Infection with chikungunya virus in Italy: an outbreak in a temperate region. Lancet. 2007;370(9602):1840-6. http:// dx.doi.org/10.1016/S0140-6736(07)61779-6

22. Angelini R, Finarelli AC, Angelini P, Po C, Petropulacos K, Silvi $\mathrm{G}$, et al. Chikungunya in north-eastern Italy: a summing up of the outbreak. Euro Surveill. 2007;12(47):pii=3313.

23. Charrel RN, de Lamballerie X, Raoult D. Seasonality of mosquitoes and chikungunya in Italy. Lancet Infect Dis. 2008;8(1):5-6. http://dx.doi.org/10.1016/ S1473-3099(07)70296-7

24. Frank C, Schoneberg I, Stark K. Trends in imported chikungunya virus infections in Germany, 2006-2009. Vector-Borne Zoonotic Dis. 2011;11(6):631-6. http://dx.doi. org/10.1089/vbz.2010.0269

25. Petersen LR, Stramer SL, Powers AM. Chikungunya virus: possible impact on transfusion medicine. Transfus Med Rev. 2010;24(1):15-21. http://dx.doi.org/10.1016/j. tmrv.2009.09.002

26. Medlock JM, Hansford KM, Schaffner F, Versteirt V, Hendrickx $\mathrm{G}$, Zeller H, et al. A Review of the Invasive Mosquitoes in Europe: Ecology, Public Health Risks, and Control Options. Vector-Borne Zoonotic Dis. 2012;12(6):435-47. http://dx.doi. org/10.1089/vbz.2011.0814

27. Tran A, L'Ambert G, Lacour G, Benoit R, Demarchi M, Cros M, et al. A rainfall- and temperature-driven abundance model for Aedes albopictus populations. Int J Environ Res Public
Health. 2013;10(5):1698-719. http://dx.doi.org/10.3390/ ijerph10051698

28. Vega-Rua A, Zouache K, Caro V, Diancourt L, Delaunay P, Grandadam M, et al. High efficiency of temperate Aedes albopictus to transmit chikungunya and dengue viruses in the Southeast of France. PloS one. 2013;8(3):e59716. http:// dx.doi.org/10.1371/journal.pone.0059716

29. McIntosh BM, Harwin RM, Paterson HE, Westwater ML. An Epidemic of Chikungunya in South-Eastern Southern Rhodesia. Cent Afr J Med. 1963;43:351-9.

30. Jadhav M, Namboodripad M, Carman RH, Carey DE, Myers RM. Chikungunya disease in infants and children in Vellore: a report of clinical and haematological features of virologically proved cases. Indian J Med Res. 1965;53(8):764-76.

31. Myers RM, Carey DE, Reuben R, Jesudass ES, De Ranitz C, Jadhav M. The 1964 epidemic of dengue-like fever in South India: isolation of chikungunya virus from human sera and from mosquitoes. Indian J Med Res. 1965;53(8):694-701.

32. Moore DL, Reddy S, Akinkugbe FM, Lee VH, David-West TS, Causey OR, et al. An epidemic of chikungunya fever at Ibadan, Nigeria, 1969. Ann Trop Med Parasitol. 1974;68(1):59-68.

33. Khai Ming C, Thain S, Thaung U, Tin U, Myint KS, Swe T, et al. Clinical and laboratory studies on haemorrhagic fever in Burma, 1970-72. Bull World Health Organ. 1974;51(3):227-35.

34. Filipe AF, Pinto MR. Arbovirus studies in Luanda, Angola. 2. Virological and serological studies during an outbreak of dengue-like disease caused by the Chikungunya virus. Bull World Health Organ. 1973;49(1):37-40.

35. Tomori O, Fagbami A, Fabiyi A. The 1974 epidemic of Chikungunya fever in children in Ibadan. Trop Geogr Med. 1975;27(4):413-7.

36. Morrison JG. Chikungunya fever. Int J Dermatol. 1979;18(8):628-9. http://dx.doi.org/10.1111/j.1365-4362.1979 tbo4677.x

37. Padbidri VS, Gnaneswar TT. Epidemiological investigations of chikungunya epidemic at Barsi, Maharashtra state, India. J Hyg Epidemiol Microbiol Immunol. 1979;23(4):445-51.

38. Saluzzo JF, Gonzalez JP, Herve JP, Georges AJ. [Epidemiological study of arboviruses in the Central African Republic: demonstration of Chikungunya virus during 1978 and 1979]. Bull Soc Pathol Exot Filiales. 1980 Jul-Aug;73(4):390-9. French.

39. Brighton SW, Prozesky OW, de la Harpe AL. Chikungunya virus infection. A retrospective study of 107 cases. S Afr Med J. 1983;63(9):313-5.

40. Saluzzo JF, Cornet M, Digoutte JP. [Outbreak of a Chikungunya virus epidemic in western Senegal in 1982]. Dakar Med. 1983;28(3):497-500. French.

41. Centers for Disease Control (CDC). Chikungunya fever among U.S. Peace Corps volunteers--Republic of the Philippines. MMWR Morb Mortal Wkly Rep. 1986;35(36):573-4.

42. Rodhain F, Carteron B, Laroche R, Hannoun C. [Human arbovirus infections in Burundi: results of a seroepidemiologic survey, 1980-1982]. Bull Soc Pathol Exot Filiales. 1987;80(2):155-61.

43. Rodhain F, Gonzalez JP, Mercier E, Helynck B, Larouze B, Hannoun C. Arbovirus infections and viral haemorrhagic fevers in Uganda: a serological survey in Karamoja district, 1984. Trans R Soc Trop Med Hyg. 1989;83(6):851-4. http://dx.doi. org/10.1016/0035-9203(89)90352-0

44. Dash AP, Bhatia R, Sunyoto T, Mourya DT. Emerging and reemerging arboviral diseases in Southeast Asia. J Vector Borne Dis. 2013;50(2):77-84.

45. Ivanov AP, Ivanova OE, Lomonosov NN, Pozdnyakov SV, Konstantinov OK, Bah MA. Serological investigations of Chikungunya virus in the Republic of Guinea. Ann Soc Belg Med Trop. 1992;72(1):73-4.

46. Thaikruea L, Charearnsook O, Reanphumkarnkit S, Dissomboon P, Phonjan R, Ratchbud S, et al. Chikungunya in Thailand: a reemerging disease? Southeast Asian J Trop Med Public Health. 1997;28(2):359-64.

47. Lam SK, Chua KB, Hooi PS, Rahimah MA, Kumari S, Tharmaratnam $M$, et al. Chikungunya infection--an emerging disease in Malaysia. Southeast Asian J Trop Med Public Health. 2001;32(3):447-51.

48. Muyembe-Tamfum JJ, Peyrefitte CN, Yogolelo R, Mathina Basisya E, Koyange D, Pukuta E, et al. [Epidemic of Chikungunya virus in 1999 and 200 in the Democratic Republic of the Congo]. Med Trop. 2003;63(6):637-8. French.

49. Porter KR, Tan R, Istary Y, Suharyono W, Sutaryo, Widjaja S, et al. A serological study of Chikungunya virus transmission in Yogyakarta, Indonesia: evidence for the first outbreak since 1982. Southeast Asian J Trop Med Public Health. 2004;35(2):408-15. 
50. Chastel C. [Chikungunya virus: its recent spread to the southern Indian Ocean and Reunion Island (2005-2006)]. Bull Acad Natl Med. 2005;189(8):1827-35. French.

51. Outbreak news. Chikungunya and dengue, south-west Indian Ocean. Wkly Epidemiol Rec. 2006;81(12):106-8.

52. Outbreak news. Chikungunya, India. Wkly Epidemiol Rec. 2006;81(43):409-10.

53. Bonn D. How did chikungunya reach the Indian Ocean? Lancet Infect Dis. 2006;6(9):543. http://dx.doi.org/10.1016/ S1473-3099(06)70559-X

54. Josseran L, Paquet C, Zehgnoun A, Caillere N, Le Tertre A, Solet J, et al. Chikungunya disease outbreak, Reunion Island. Emerg Infect Dis. 2006;12(12):1994-5. http://dx.doi.org/10.3201/ eid1212.060710

55. Kalantri SP, Joshi R, Riley LW. Chikungunya epidemic: an Indian perspective. Natl Med J India. 2006;19(6):315-22.

56. Kumarasamy V, Prathapa S, Zuridah H, Chem YK, Norizah I, Chua KB. Re-emergence of Chikungunya virus in Malaysia. Med J Malaysia. 2006;61(2):221-5.

57. Seneviratne SL, Perera J. Fever epidemic moves into Sri Lanka. BMJ. 2006;333(7580):1220-1. http://dx.doi.org/10.1136/ bmj.39051.725729.3A

58. Peyrefitte CN, Rousset D, Pastorino BA, Pouillot R, Bessaud $M$, Tock F, et al. Chikungunya virus, Cameroon, 2006. Emers Infect Dis. 2007;13(5):768-71. http://dx.doi.org/10.3201/ eid1305.061500

59. Beesoon S, Funkhouser E, Kotea N, Spielman A, Robich RM. Chikungunya fever, Mauritius, 2006. Emerg Infect Dis. 2008;14(2):337-8. http://dx.doi.org/10.3201/eid1402.071024

6o. Gould LH, Osman MS, Farnon EC, Griffith KS, Godsey MS, Karch S, et al. An outbreak of yellow fever with concurrent chikungunya virus transmission in South Kordofan, Sudan, 2005. Trans R Soc Trop Med Hyg. 2008;102(12):1247-54. http://dx.doi.org/10.1016/j.trstmh.2008.04.014

61. Peyrefitte CN, Bessaud M, Pastorino BA, Gravier P, Plumet S, Merle OL, et al. Circulation of Chikungunya virus in Gabon, 2006-2007. J Med Virol. 2008;80(3):430-3. http://dx.doi. org/10.1002/jmv.21090

62. Ratsitorahina M, Harisoa J, Ratovonjato J, Biacabe S, Reynes JM, Zeller H, et al. Outbreak of dengue and Chikungunya fevers, Toamasina, Madagascar, 2006. Emerg Infect Dis. 2008;14(7):1135-7. http://dx.doi.org/10.3201/eid1407.071521

63. D'Ortenzio E, Grandadam M, Balleydier E, Dehecq JS, Jaffar-Bandjee MC, Michault A, et al. Sporadic cases of chikungunya, Reunion Island, August 2009. Euro Surveill. 2009;14(35):pii:19324.

64. Leo YS, Chow AL, Tan LK, Lye DC, Lin L, Ng LC. Chikungunya outbreak, Singapore, 2008. Emerg Infect Dis. 2009;15(5):836-7. http://dx.doi.org/10.3201/eid1505.081390

65. Leroy EM, Nkoghe D, Ollomo B, Nze-Nkogue C, Becquart P, Grard G, et al. Concurrent chikungunya and dengue virus infections during simultaneous outbreaks, Gabon, 2007. Emerg Infect Dis. 2009;15(4):591-3. http://dx.doi.org/10.3201/ eid1504.080664

66. Theamboonlers A, Rianthavorn P, Praianantathavorn K, Wuttirattanakowit N, Poovorawan Y. Clinical and molecular characterization of chikungunya virus in South Thailand. Jpn J Infect Dis. 2009;62(4):303-5

67. Yoosuf AA, Shiham I, Mohamed AJ, Ali G, Luna JM, Pandav R, et al. First report of chikungunya from the Maldives. Trans R Soc Trop Med Hyg. 2009;103(2):192-6. http://dx.doi.org/10.1016/j. trstmh.2008.09.006

68. Chua KB. Epidemiology of chikungunya in Malaysia: 2006 2009. Med J Malaysia. 2010;65(4):277-82

69. Win MK, Chow A, Dimatatac F, Go CJ, Leo YS. Chikungunya fever in Singapore: acute clinical and laboratory features, and factors associated with persistent arthralgia. J Clin Virol. 2010;49(2):111-4. http://dx.doi.org/10.1016/j.jcv.2010.07.004

70. Chusri S, Siripaitoon P, Hirunpat S, Silpapojakul K. Case reports of neuro-Chikungunya in southern Thailand. Am J Trop Med Hyg. 2011;85(2):386-9. http://dx.doi.org/10.4269/ ajtmh.2011.10-0725

71. Qiaoli Z, Jianfeng H, De W, Zijun W, Xinguang Z, Haojie Z, et al. Maiden outbreak of chikungunya in Dongguan city, Guangdong province, China: epidemiological characteristics. PloS one. 2012;7(8):e42830. http://dx.doi.org/10.1371/journal. pone. 0042830

72. Singh $P$, Mittal V, Rizvi MM, Chhabra M, Sharma P, Rawat DS, et al. The first dominant co-circulation of both dengue and chikungunya viruses during the post-monsoon period of 2010 in Delhi, India. Epidemiol Infect. 2012;140(7):1337-42. http:// dx.doi.org/10.1017/S0950268811001671

73. Wu D, Wu J, Zhang Q, Zhong H, Ke C, Deng X, et al. Chikungunya outbreak in Guangdong Province, China, 2010.
Emerg Infect Dis. 2012;18(3):493-5. http://dx.doi.org/10.3201/ eid1803.110034

74. Mombouli JV, Bitsindou P, Elion DO, Grolla A, Feldmann H, Niama FR, et al. Chikungunya virus infection, Brazzaville, Republic of Congo, 2011. Emerg Infect Dis. 2013;19(9):1542-3. http://dx.doi.org/10.3201/eid1909.130451

75. Wu D, Zhang Y, Zhouhui Q, Kou J, Liang W, Zhang H, et al. Chikungunya virus with $\mathrm{E}_{1}-\mathrm{A} 226 \mathrm{~V}$ mutation causing two outbreaks in 2010, Guangdong, China. Virol J. 2013;10:174. http://dx.doi.org/10.1186/1743-422X-10-174

76. Centers for Disease Control and Prevention (CDC). Chikungunya outbreak--Cambodia, February-March 2012. MMWR Morb Mortal Wkly Rep. 2012;61:737-40.

77. Soulaphy C, Souliphone P, Phanthavong K, Phonekeo D, Phimmasine S, Khamphaphongphane B, et al. Emergence of chikungunya in Moonlapamok and Khong Districts, Champassak Province,the Lao People's Democratic Republic, May to September 2012. Western Pac Surveill Response J. 2013;4(1):46-50. http://dx.doi.org/10.5365/wpsar.2012.3.4.017

78. Wangchuk S, Chinnawirotpisan P, Dorji T, Tobgay T, Dorji T, Yoon IK, et al. Chikungunya fever outbreak, Bhutan, 2012. Emerg Infect Dis. 2013;19(10):1681-4. http://dx.doi. org/10.3201/eid1910.130453

79. Zayed A, Awash AA, Esmail MA, Al-Mohamadi HA, Al-Salwai $\mathrm{M}$, Al-Jasari A, et al. Detection of Chikungunya virus in Aedes aegypti during 2011 outbreak in Al Hodayda, Yemen. Acta Trop. 2012;123(1):62-6. http://dx.doi.org/10.1016/j. actatropica.2012.03.004

8o. Ansumana R, Jacobsen KH, Leski TA, Covington AL, Bangura $\mathrm{U}$, Hodges $\mathrm{MH}$, et al. Reemergence of chikungunya virus in Bo, Sierra Leone. Emerg Infect Dis. 2013;19(7):1108-10. http:// dx.doi.org/10.3201/eid1907.121563

81. Horwood PF, Reimer LJ, Dagina R, Susapu M, Bande G, Katusele $M$, et al. Outbreak of chikungunya virus infection, Vanimo, Papua New Guinea. Emerg Infect Dis. 2013;19(9):1535-8. http://dx.doi.org/10.3201/eid1909.130130 